\title{
KAJIAN PROBLEMATIKA DAN STANDARISASI ASISTEN LABORATORIUM DI PERGURUAN TINGGI
}

\author{
Hikmah Fatimah ${ }^{1}$, Dimas Fahrudin ${ }^{2}$ dan Emy Shofiah S. ${ }^{3}$ \\ 1,2,3 Program Studi S2 Pendidikan Sains, Fakultas Keguruan dan Ilmu Pendidikan, Universitas Sebelas Maret \\ Surakarta, 57126, Indonesia
}

Email: ${ }^{1}$ hikmahfatimah2@gmail.com; ${ }^{2}$ dimasfahr@student.uns.ac.id; ${ }^{3}$ emyshofiahsetyowati@ student.uns.ac.id

Diajukan: 8 Agustus 2021; Diterima: 9 September 2021; Diterbitkan: 30 Oktober 2021

\begin{abstract}
Abstrak: Perbedaan manajemen asisten dosen laboratorium pada berbagai jensi laboratorium disebabkan oleh adanya perbedaan kebijakan setiap kepala laboratorium. Untuk itu, dilakukan kajian mengenai problematika dan standarisasi asisten laboratorium di perguruan tinggi, utamanya prodi pendidikan sains pada jenjang sarjana. Penelitian dilakukan menggunakan pendekatan deskriptif kualitatif untuk menganalisis input, proses dan output dalam Perguruan Tinggi. Data kualitatif diperoleh melalui kegiatan wawancara kepada asisten dosen di beberapa perguruan tinggi seperti Universitas Negeri Malang, Universitas Negeri Jember dan Universitas Sebelas Maret. Wawancara berisi pertanyaan terkait proses perekrutan, kegiatan dalam laboratorium saat praktikum dan setelah praktikum serta reward yang didapatkan setelah menjadi asisten dosen laboratorium. Hasil yang diperoleh bahwa manajemen laboratorium mengenai asisten laboratorium dilapangan menemui beberapa permasalahan seperti tidak ada standarisasi terkait syarat/kualifikasi perekrutan asisten laboratorium, tidak ada honorarium, dan mahasiswa tidak mendapat sertifikasi setelah selesai melaksanakan tugas. Selain itu, belum terdapat standarisasi manajemen asisten dosen laboratorium dalam skala nasional.
\end{abstract}

Kata kunci: Problematika, Standarisasi, Asisten Laboratorium

Abstract: Differences in the management of laboratory assistant lecturers in various types of laboratories are caused by differences in the policies of each laboratory head. For this reason, a study was carried out on the problems and standardization of laboratory assistants in universities, especially science education study programs at the undergraduate level. The research was conducted using a qualitative descriptive approach to analyze input, process and output in higher education. Qualitative data were obtained through interviews with teaching assistants at several universities such as Malang State University, Jember State University and Sebelas Maret University. The interview contains questions related to the recruitment process, activities in the laboratory during practicum and after practicum as well as rewards obtained after becoming a laboratory lecturer assistant. The results obtained are that laboratory management regarding laboratory assistants in the field encounters several problems such as there is no standardization regarding the requirements/qualifications for the recruitment of laboratory assistants, there is no honorarium, and students do not receive certification after completing their assignments. In addition, there is no standardized management of laboratory assistant lecturers on a national scale.

Keywords: Problematics, Standardization, Laboratory Assistant

\section{Pendahuluan}

Peneliti pendidikan sains selama beberapa dekade terakhir telah menyarankan bahwa peranan laboratorium sangat bermanfaat bagi mahamahasiswa untuk meningkatkan kualitas dan kekayaan proses berfikir serta keteramilan proses sains. Laboratorium menjadi tempat bagi mahamahasiswa untuk memperoleh pengalaman secara empiris untuk mengasah keterampilan proses sains. Selama proses pembelajaran praktikum mahamahasiswa dapat mengembangkan pemikiran yang kreatif, rasa ingin tahu serta mengembangkan keterampilan berfikir untuk memecahkan masalah. Keberadaan laboratorium tidak dapat terpisahkan dari keberhasilan dalam praktikum pembelajaran sains, maka dari itu perencanaan, manajemen hingga evaluasi kinerja laboratorium penting untuk dicermati untuk memberikan pelayaan yan 
prima kepada mahasiswa untuk mendukung proses pembelajaran yang optimal (Jaya, 2014).

Praktikum pada laboratorium sains yang mendukung dan mendorong pembelajaran adalah kunci untuk setiap pelajaran sains yang baik. Pola berfikir kritis mengenai Bagaimana, apa, dan mengapa suatu hal dapat terjadi yang diajukan pada mahasiswa dapat memicu penyelidikan lebih lanjut ketika pertanyaan tesebut dipindahkan ke laboratorium sains sekolah. Pengalaman kehidupan nyata dan ilmu praktis seperti mengapa daun berwana hijau, bagaimana tumbuhan menghasilkan oksigen dapat dijawab oleh mahasiswa apabila permasalahan tersebut dibawa keranah ilmiah dan dipecahkan oleh mahasiswa melalui aktivitas di laboratorium (Simatupang, 2018).

Laboratorium sains yang terkelola dengan baik menciptakan lingkungan kerja yang tidak hanya menguntungkan mahasiswa tetapi juga guru. Pengelolaan laboratorium sains diharapkan dapat memastikan bahwa setiap laboratorium perguruan tinggi secara efektif hendaknya dapat menarik dan menginspirasi mahasiswa untuk menjadi seorang generasi ilmuwan yang memiliki rasa ingin tahu tinggi (Pertiwi, 2019). Pertama dan yang paling utama adalah tempat untuk eksperimen. Pada saat proses praktikum berlangsung mahasiswa melaksanakan suatu eksperimen dan hal ini merupakan sebuah langkah investigasi pemecahan masalah. Pedoman kurikulum di perguruan tinggitentu telah menyarankan agar pada proses pembelajaran memasukkan eksperimen praktis pada rencana pembelajaran, jadi laboratorium sains yang selalu siap untuk beraksi sangat penting.

Pertimbangan yang cermat juga harus diberikan pada fleksibilitas ruang laboatorium sains. Hal ini penting untuk memberikan kesempatan untuk eksperimen praktis secara mandiri sebagai contoh adalah bagaimana laboratorium perguruan tinggi atau universitas dapat menjadi tempat kerja mandiri bagi mahasiswa yang sedang mengerjakan proyek karya tulis ilmiah. Disisi lain ketentuan untuk kerja kelompok kolaboratif juga sangat penting untuk menciptakan pembelajaran sains yang kolaboratif. Poin-poin tersebut diatas ini menjadi perhatian khusus setiap proses manajemen laboratorium sehingga dapat tercipta laboratorium yang terkelola dengan baik yang memungkinkan praktikum dapat mendukung proses pembelajaran sesuai dengan kurikulum, metode, dan model pembelajaran sehingga terciptanya karakter mahasiswa yang berfikir ilmiah kreatif dan inovatif. Disisi lain fasilitas laboratorium harus mendukung untuk untuk pembelajaran praktikum yang efektif: penggunaan simbol-simbol peringatan, petunjuk, serta alat dan media pembelajaran juga menjadi peralatan harus ada dalam laboratorium dan kesemuanya itu dikelola dengan tepat agar praktikum dapat dilakukan secara efisien. Laboratorium yang dikelola dengan baik memungkinkan kenyamanan penggunaan dalam proses pembelajaran baik secara teoretis maupun investigasi praktis (Wahyuningtyas, 2021).

Beberapa penjelasan di atas telah menerangkan pentingnya laboratorium dalam mendukung pembelajaran, pentingnya manajemen laboratorium dalam menunjang daya dukung laboratorium dalam pembelajaran (Sulviyana, 2017). Namun demikian terdapat satu komponen penting dari proses bekerja di laboratorium yaitu asisten praktikum atau asisten laboran. Asisten praktikum atau asisten laboratorium merupakan seseorang yang ditunjuk oleh guru atau dosen untuk memandu peserta didik dalam melaksanakan kegiatan praktikkum. Selain sebagai pemandu tidak jarang asisten juga berfungsi sebagai evaluator kinerja praktikum peserta didik (Hadiati, 2020). Dari pernyataan diatas dapat diketahui bahwa asisten praktikum atau asisten laboratorium memegang peranan penting dalam proses pembelajaran praktikum. 
Berdasarkan hasil studi pendahuluan awal dengan wawancara berbagai alumni asisten laboratorium, telah diketahui bahwa manajemen asisten praktikum maupun asisten laboratorium sangat berbeda antara satu laboratorium dengan yang lainya. Dengan demikian Kajian pada penelitian ini berusaha untuk mengindentifikasi berbagai pola manajemen laboratorium diberbagai perguruan tinggi terutama pada prodi pendidikan sains pada jenjang sarjana. Kajian manajemen asisten laboratorium ini berfokus pada bagaimana bagaimana sistem perekrutan asisten laboratorium untuk menetukan standar kelayakan suatu asisten praktikum atau laboratorium. Penelitian ini juga berusaha untuk mengkaji bagaiman pola Manajemen serta evaluasi dari seorang asisten praktikum/laboratorium. Kajian lebih lanjut secara kompehensif tentu perlu dilakukan terutama pada bagaiman merancang model standarisasi asisten laboratorium agar dapat optimal dalam membantu proses praktikum dalam pembelajaran sains baik di perguruan tinggimaupun di universitas.

\section{Metode}

Kajian probmelatika dan standarisasi sisten laboratorium ini dilakukan menggunakan pendekatan deskriptif kualitatif untuk menganalisis input, proses dan output dalam Perguruan Tinggi. Data kualitatif diperoleh melalui kegiatan wawancara kepada asisten dosen di beberapa perguruan tinggi seperti Universitas Negeri Malang, Universitas Negeri Jember dan Universitas Sebelas Maret. Wawancara berisi pertanyaan terkait proses perekrutan, kegiatan dalam laboratorium saat praktikum dan setelah praktikum serta reward yang didapatkan setelah menjadi asisten dosen laboratorium.

\section{Pembahasan}

Kegiatan praktikum di perguruan tinggi dilaksanakan di laboratorium, karena laboratorium penggunanya banyak, maka dibentuklah manajemen laboratorium. Manajemen laboratorium salah satunya adalah membutuhkan asisten laboratorium untuk membatu dalam penyelenggaraan praktikum. Karena membutuhkan asisten laboratorium maka dari itu dosen atau laboran membuka perekrutan aisten laboratorium.

Perekrutan asisten laboratorium di beberapa Perguruan Tinggi memiliki syarat yang berbeda-beda. Berdasarkan hasil wawancara yang telah dilakukan, semua nara sumber menyatakan bahwa dalam perekrutan asisten dosen laboratorium mensyaratkan IPK sebagai syarat dalam perekrutan asisten laboratorium di perguruan tinggi. Syarat untuk dapat menjadi asisten laboratorium adalah mahasiswa yang memiliki IPK lebih dari 2.75 berdasarkan dari hasil wawancara oleh beberapa narasumber dari berbagai perguruan tinggi.

Syarat perekrutan asisten laboratorium juga dilihat dari aspek mata kuliah terkait praktikum. Nilai mata kuliah terkait praktikum berbeda-beda tiap mata kuliahnya. Berdasarkan hasil wawancara yang telah dilakukan, untuk perekrutan asisten laboratoriun dengan syarat nilai mata kuliah A ada sebanyak 9,5\% dari total responden atau 2 mahasiswa dari 21 mahasiswa, untuk nilai A- sebanyak 14,3\% atau sebanyak 3 mahasiswa, untuk B+ sebanyak $47,6 \%$ atau sekitar 10 mahasiswa, dan nilai B sebesar 28,6\% atau sebanyak 6 mahasiswa. Jadi sebagian besar syarat untuk menjadi asisten laboratorium adalah mahasiswa yang mempunyai nilai $\mathrm{B}+$ untuk mata kuliah terkait praktikum.

Terkait semester minimal bagi calon asisten laboratorium dibeberapa perguruan tinggi adalah mahasiswa minimal semester 3. Dan setiap semesternya maksimal menjadi asisten laboratorium maksimal 1 kali. Tidak ada syarat terkait gender dalam perekrutan asisten 
laboratorium di perguruan tinggi. Syarat lain bagi mahasiswa yang ingin menjadi asisten laboratorium adalah sudah menempuh mata kuliah terkait dan sudah lulus mata kyliah tersebut, selain itu juga tidak ada jam kuiah pada saat berlangsungnya praktikum.

Hasil wawancara dari beberapa narasumber, untuk test dalam perekrutan asisten laboratorium sebaiknya ditambah dengan wawancara serta kejelasan syarat dan ketentuan dalam perekrutan. Setelah diterima dijelaskan apa saja yang harus dilakukan pada saat menjadi aisten laboratorium. Dan setelah selesai melaksanakan tugas sebaiknya diadakan evaluasi agar kualitas asisten laboratorium semakin baik.

Setelah mahasiswa terpilih untuk menjadi asisten laboratorium, sebagian besar narasumber menyatakan bahwa mereka pada saat menjadi asisten laboratorium tidak digaji. 5 dari 21 mahasiswa sebagai narasumber yang digaji sedangkan sisanya tidak digaji. Bagi narasumber yang digaji, rata-rata mereka digaji 25.00035.000 setiap pertemuan. Rata-rata mereka berkerja selama 3-4 jam dan mereka bertugas dalam menyiapkan alat praktikum, membantu dalam pelaksanaan praktikum dan memberishkan alat dan ruangan pada saat praktikum sudah selesai.

Sertifikasi didapatkan setelah mahasiswa telah selesai dalam pelaksaanaan praktikum tetapi ada juga yang mendapat SK atau sertifikasi harus menunggu lama dan harus aktif bertanya perihal HAK yang mereka dapat setelah selesai menjadi asisten laboratorium bahkan ada juga yang tidak mendapatkan sertifikasi. Sebagian besar tidak ada reward setelah melaksanakan praktikum, tatapi terkadang mereka mendapatkan konsumsi atau uang pulsa.

Dalam manajemen laboratorium mengenai asisten laboratorium dilapangan menemui beberapa permasalahan seperti tidak ada standarisasi terkait syarat/kualifikasi perekrutan asisten laboratorium, tidak ada honorarium, dan mahasiswa tidak mendapat sertifikasi setelah selesai melaksanakan tugas.

Kegiatan rekrutmen asisten dosen laboratorium dilaksankan setiap semester sesuai kebutuhan mata kuliah praktikum yang ada. Keputusan rekrutmen asisten dosen laboratorium merupakan tugas kepala laboratorium yang sangat berdampak pada manajemen laboratorium. Asisten dosen laboratorium merupakan mahasiswa yang sedang menempuh S1 yang telah memenuhi kriteria yang telah ditetapkan.

Melalui perekrutan asisten dosen laboratorium diharapkan mampu menjadi motivator mahasiswa dalam proses belajar(Tanojo, 2015). Pada umunya proses perekrutan asisten dosen laboratoium menggunakan kriteria akademik dan non akademik (Mardiana, 2014). Berdasarkan studi literature, persayaran kualifikasi asisten dosen untuk setiap universitas berbeda-beda. Berikut kualifikasi yang dibutuhkan untuk menjadi asisten dosen laboratorium :

1. Universitas Muhammadiyah

a. Mahasiswa dengan semester tertentu diatas mata kuliah yang akan dituju(misalnya semester 5)

b. Mahasiswa memiliki IPK $>3$

c. Mahasiswa memiliki nilai minimal B pada beberapa mata kuliah inti

d. Mahasiswa mengikuti tes tulis dan tes computer

e. Mahasiswa melaksanakan tes microteaching

f. mahasiswa melaksanakan tes wawancara

2. STIE Trisakti

a. Mahasiswa sudah mengambil mata kuliah minimal 88 SKS

b. Mahasiswa memiliki IPK $>3$

c. Mahasiswa memiliki nilai minimal B pada beberapa mata kuliah tertentu yang telah ditetapkan

d. Mahasiswa memiliki sertifikat tertentu sesuai dengan laboratorium yang dituju 


\section{Universitas Teuku Umar}

a. Mahasiswa aktif

b. Mahasiswa telah mengambil/lulus mata kuliah yang didaftarkan pada semester sebelumnya

c. Mahasiswa memiliki IPK>3

d. Mahasiswa mengikuti seleksi calon asisten dosen laboratorium hingga akhir

e. Mahasiswa rajin dan taat pada peraturan

4. Universitas Pertamina

a. Mahasiswa minimal semester 5

b. Mahasiswa telah mengambil/lulus mata kuliah yang didaftarkan pada semester sebelumnya

c. Mahasiswa memahami bahasa pemograman

d. Mahasiswa mengikuti seleksi administrasi, seleksi pemograman dan simulasi praktikum

5. Universitas Sanata Dharma

a. Mahasiswa memiliki IPK $>2,8$

b. Mahasiswa telah mengambil/lulus mata kuliah yang didaftarkan pada semester sebelumnya

c. Mahasiswa mengikuti seleksi administrasi, wawancara dan kompetensi

\section{UGM}

a. Mahasiswa telah menempuh semester 6 pada jenjang sarjana, dan telah menempuh semester 4 pada jenjang diploma

b. Mahasiswa memiliki IPK >3

c. Mahasiswa memiliki nilai minimal B pada beberapa mata kuliah tertentu yang telah ditetapkan

d. Mahasiswa diperbolehkan menjadi asisten dosen laboratorium maksimal 2 mata kuliah

Tugas dan kewajiban asisten dosen laboratorium berbeda-beda berdasarkan peraturan yang telah ditetapkan oleh prodi, jurusan, fakultas dan universitas. Hasil yang didapatkan setelah menjadi asisten dosen laboratorium yaitu mendapatkan sertifikat, honorarium dan kemampuan tertentu sesuai dengan mata kuliah. Honorarium diberikan atas dasar pelaksanaan tugas tembahan/ khusus pada bisang akademik dan kemahasiswaan.

Berdasarkan hasil wawancara dan studi literature didapatkan honorarium yang diperoleh mahasiswa berkisar antara Rp. 25.000- Rp. 60.000 setiap pertemuan. Besaran honorarium yang diberikan kepada asisten dosen laboratorium disesuaikan dengan kemampuan keuangan setiap perguruan tinggi melalui peraturan pimpinan/rektor yang bersangkutan. Sumber pembiaayaan satuan pendidikan berasal dari PNBP, dalam hal honorarium maka menggunakan sumber pendapatan lain setiap perguruan tinggi. Penetapan honorarium harus mempertimbangkan prinsip penngelolaan keuangan negara yang meliputi tertib, taat peraturan prundang-undangan, efisien, ekonomis, efektif, transparan dan bertanggung jawab dengan memperhatikan rasa keadilan dan kepatuhan (Illahi, 2017).

Berdasarkan Surat Edaran (SE) Menteri Ketenagakerjaan Nomor Bm/308/HI.01.00/X/2019 tanggal 15 Oktober 2019, besar UMR per tahun 2019 di jawa barat sebesar $\mathrm{Rp}$ 1.810.350, jawa timur sebesar $\mathrm{Rp}$ 1.768.777 dan jawa tengah sebesar Rp 1.742.015. Dari angka tersebut diperoleh upah per hari sebesar Rp.58.000-Rp.60.000 dan setiap jam sebesar Rp.13.825-Rp.14.400. Namun, dalam UU Omnibuslaw pasal 16 ayat 1 berbunyi "penetapan upah per jam hanya dapat diperuntukkan bagi pekerja atau buruh yang bekerja secara paruh waktu". Besar honorarium asisten laboratorium setiap jam sebesar Rp.5000Rp.12.000.

Sehingga honorarium asisten dosen laboratorium di perguruan tinggi dapat dikatan sangat layak. Karena asisten dosen laboratorium hanya bekerja maksimal 5 jam perhari mendapatkan gaji yang hapir sama dengan pekerja/buruh yang bekerja selama 7-8 jam perhari (Undang Undang Republik Indonesia 
Nomor 11 Tahun 2020 Tentang Cipta Kerja, 2020).

\section{Kesimpulan}

Kesimpulan dari penelitian ini menunjukan bahwa problematika yang muncul pada manajemen asisten laboratorium pendidikan sains antara satu dengan lainya sangat berbeda perbedaan terletak pada sistem perekrutan, pengelolaan dan output. Problematika yang umum ditemui dalam manajen asisten laboratorium adalah terkait dengan gaji asisten dan evaluasi kinerja asisten.

Hasil yang diperoleh bahwa manajemen laboratorium mengenai asisten laboratorium dilapangan menemui beberapa permasalahan seperti tidak ada standarisasi terkait syarat/kualifikasi perekrutan asisten laboratorium, tidak ada honorarium, dan mahasiswa tidak mendapat sertifikasi setelah selesai melaksanakan tugas. Selain itu, belum terdapat standarisasi manajemen asisten dosen laboratorium baik dalam skala lokal maupun skala nasional.

\section{Saran}

Kajian pada penelitian ini fokus menemukan permasalahan. Selanjutnya sangat diperlukan penelitian terkait model manajemen asisten laboratorium IPA yang baku sehingga peran asisten dalam mendukung proses pembelajaran Praktikum Sains di laboratorium dapat dioptimalkan.

\section{DAFTAR PUSTAKA}

Hadiati, S., Anita, A. and Pramuda, A., 2020. Pengembangan Instrumen Penilaian Afektif Pada Asisten Praktikum Laboratorium Fisika. Radiasi: Jurnal Berkala Pendidikan Fisika, 13(2), pp.3539.
Illahi, B. K. (2017). Konstitusionalitas Sistem Pertanggungjawaban Keuangan Negara Ditinjau Dari Aspek Kelembagaan Pengawasan Keuangan Negara. Universitas Andalas.

Jaya, H., 2014. Analisis dan Perancangan Sistem Laboratorium Simulasi Berbasis Web. JETC" Jurnal Elektronika Telekomunikasi \& Computer", 9(1), pp.75-90.

Juddah, S., Attar, M. and Sutrisno, M.2021, Kajian Pencahayaan Alami Pada Ruang Laboratorium Fakultas Sains dan Teknologi UIN Alauddin Makassar. TEKNOSAINS: Media Informasi Sains dan Teknologi, 15(1), pp.48-57.

Mardiana, T. (2014). Sistem Pendukung Keputusan Penerimaan Asisten Laboratorium Komputer Menggunakan Metode AHP-TOPSIS. JITK (Jurnal Ilmu Pengetahuan Dan Teknologi Komputer), 3(2), 159-166.

Pertiwi, F.N., 2019. Sistem Pengelolaan (Perencanaan, Pelaksanaan, evaluasi) Laboratorium IPA SMP Negeri Di Ponorogo. Jurnal Penelitian Islam, 13(1).

Simatupang, A.C. and Sitompul, A.F., 2018. Analisis Sarana dan Prasarana Laboratorium Biologi dan Pelaksanaan Kegiatan Praktikum Biologi dalam Mendukung Pembelajaran Biologi Kelas XI. Jurnal Pelita Pendidikan, 6(2).

Sulviyana, Y., Tejawati, A. and Hairah, U., 2017, September. Sistem Pendukung Keputusan Seleksi Penerimaan Calon Asisten Praktikum Menggunakan Metode SMART. In Prosiding Seminar Nasional Ilmu Komputer dan Teknologi Informasi (Vol. 2, No. 2). 
Tanojo, K. L. (2015). Identifikasi Kompetensi Asisten Mahasiswa Dan Penerapannya Pada Rancangan Sosialisasi Dan Rancangan Rekrutmen Dan Seleksi. Gema Aktualita, 4(2), 58-65.

Undang Undang Republik Indonesia Nomor 11 Tahun 2020 Tentang Cipta Kerja (Issue SK No.052692). (2020).

Wahyuningtyas, E., Syidada, S. and Pratama, F., 2021. Perancangan Sistem Manajemen Laboratorium Untuk Mendukung Pengembangan Smart Campus. JUSTINDO (Jurnal Sistem dan Teknologi Informasi Indonesia), 6(1), pp.1-8. 